\title{
Cancer stem cells in esophageal squamous cell cancer (Review)
}

\author{
QIAN WU ${ }^{1,2^{*}}$, ZHE WU $^{1 *}$, CUIYU BAO ${ }^{2 *}$, WENJING LI $^{1 *}$, HUI HE $^{1}$, \\ YANLING SUN $^{1}$, ZIMIN CHEN ${ }^{1}$, HAO ZHANG $^{3}$ and ZHIFENG NING ${ }^{1}$ \\ ${ }^{1}$ Basic Medical School; ${ }^{2}$ Nurse School, Hubei University of Science and Technology, Xianning, Hubei 437100; \\ ${ }^{3}$ Basic Medical School, Ji'nan University Medical School, Guangzhou, Guangdong 510632, P.R. China
}

Received August 30, 2018; Accepted May 29, 2019

DOI: $10.3892 / 01.2019 .10900$

\begin{abstract}
Cancer stem cells (CSCs) are hypothesized to govern the origin, progression, drug resistance, recurrence and metastasis of human cancer. CSCs have been identified in nearly all types of human cancer, including esophageal squamous cell cancer (ESCC). Four major methods are typically used to isolate or enrich CSCs, including: i) fluorescence-activated cell sorting or magnetic-activated cell sorting using cell-specific surface markers; ii) stem cell markers, including aldehyde dehydrogenase 1 family member A1; iii) side population cell phenotype markers; and iv) microsphere culture methods. ESCC stem cells have been identified using a number of these methods. An increasing number of stem cell signatures and pathways have been identified, which have assisted in the clarification of molecular mechanisms that regulate the stemness of ESCC stem cells. Certain viruses, such as human papillomavirus and hepatitis B virus, are also considered to be important in the formation of CSCs, and there is a crosstalk between stemness and viruses-associated genes/pathways, which may suggest a potential therapeutic strategy for the eradication of CSCs. In the present review, findings are summarized along these lines of inquiry.
\end{abstract}

\section{Contents}

1. Introduction

2. Isolation of CSCs from ESCC

3. Cell surface markers

4. Serum-free suspension culture

5. Side population cells

6. ALDH1

Correspondence to: Professor Zhifeng Ning, Basic Medical School, Hubei University of Science and Technology, 88 Xianning Avenue, Xianning, Hubei 437100, P.R. China

E-mail: ningzhifeng1976@163.com

*Contributed equally

Key words: esophageal squamous cell cancer, cancer stem cell, isolation, identification, signaling pathway
7. Identification of ESCC CSCs

8. Signaling pathways dysregulated in ESCC CSCs

9. Signaling pathway differences between normal and CSCs

10. Virus and ESCC stem cells

11. Conclusion

\section{Introduction}

Cancer is one of the most devastating diseases afflicting humans, not only because it negatively affects the health and quality of life of patients, but also because it places a great burden on society as a whole (1). A significant amount of progress in cancer treatment has been made over the last two decades; however, For all cancers combined, the 5-year relative survival rate of patients at advance stages with cancer remains less than $20 \%$ during the most recent time period (2007-2013) in United States (2). Surgery, chemotherapy and radiotherapy are currently the main forms of cancer treatment; however, novel therapeutic approaches, including precision treatment (3), personalized therapy (4), molecular target therapy (5), complex immunologic therapy (6) and endocrine therapy $(7,8)$, have also emerged. In addition, targeting cancer stem cells (CSCs) is an approach that has attracted an increasing amount of attention in cancer research, both in the lab and in clinical settings $(9,10)$.

In the early 20th century, Rous (11) reported that cancer resembles embryonic tissues, to a certain degree, which led to the speculation that cancer may originate from certain types of stem cells. However, Rous's speculation did not draw much attention until 1997, when Bonnet and Dick (12) demonstrated that, in acute myeloid leukemia, cancer cells are heterogeneous instead of homogeneous. Normal stem cells are now being viewed as the primary source of CSCs, which are also known as cancer stem cells (CSCs) and tumor initiating cells, since genetic mutations in these cells result in cancer and other malignant tumors, which is mediated by the acquirement of self-renewal ability. CSCs originate from stem cells or progenitor cells in transformed tissues through deregulated self-renewal (13). In addition, CSCs have been identified and later isolated from a variety of different cancer types such as in acute myeloid leukemia (14), and several solid tumors including breast cancer (15), glioblastoma (16), prostate cancer (17) and colon cancer $(18,19)$. All CSCs share the following three major characteristics: i) Unlimited proliferation: ii) self-renewal, 
and iii) multiple differentiation. In addition, the asymmetric division of CSCs can produce entire tumors that resemble the primary tumor. CSCs originate from the mutation of normal tissue stem cells or the dedifferentiation of differentiated tissue cells (Fig. 1). Different experimental strategies have been used to examine stemness. For example, MTT and/or CCK-8 assays can examine proliferation ability (20). In addition, microsphere formation can be used to investigate self-renewal ability and enrich CSCs, since only the CSCs can form microspheres when cultured in suspension without serum but with growth factors, including epidermal growth factor, basic fibroblast growth factor, B27 and insulin. However, limited dilution combined with xenograft in immune deficient mice is the gold standard in testing for cell stemness (21).

As one of the most prevalent and deadly malignancies in China, esophageal cancer with respective modality and mortality rates of 478 and 375 per 10,000, has become the focus of an increasing number of studies (1). Among different types of esophageal cancer, squamous cell cancer is the most common malignancy among the Chinese population (22). The present review will focus on the role of CSCs in esophageal squamous cell cancer (ESCC), including their incidence and 5-year survive rate, isolation, identification, signaling pathways, association with viral infection, and their involvement in diagnosis and treatment.

\section{Isolation of CSCs from ESCC}

ESCC is a common malignant tumor of the digestive tract, and relapse and metastasis to surrounding lymphatic nodes are major traits of ESCC (23). Since this type of cancer usually exhibits few or no obvious symptoms at the early stages of disease, $>50 \%$ of patients with ESCC present with metastases and unresectable tumor at the time of diagnosis (24) and the overall 5-year survive rate remains at $15-25 \%$ (25). In addition, due to the anatomical location, ESCC is difficult to completely resect, and ESCC is less sensitive to chemotherapy and radiotherapy (26). Given the important roles of CSCs in cancer initiation, progression, recurrence and metastasis (27), targeting ESCC-specific CSCs has become an attractive alternative. One of the major obstacles in CSC research and application is obtaining CSCs. There are currently four frequently used, well-established methods in CSC isolation. Although the gold standard for defining a CSC or tissue stem cell would be serial transplantation, this is a timely and costly experiment (28).

\section{Cell surface markers}

A common method used to isolate CSCs is to utilize cell surface markers, including cluster of differentiation (CD) 90 and CD44, for isolation by flow cytometry (10). This was also the earliest reported method. Using flow cytometry Bonnet and Dick (12) identified that CD34 ${ }^{++} / \mathrm{CD} 38^{-}$leukemic cells were acute myeloid leukemia stem cells in 1997. Since then, it appears that CSCs can be isolated from almost every type of cancer using this method, i.e. utilizing special cell surface markers, primarily CD molecules. Although several studies (29-32) have demonstrated an association between CDs, including CD133, and self-renewal and multidirectional differentiation abilities, it is not apparent as to why CDs can be regarded as surface markers for CSCs. Following the silencing of CD133, the stemness of CSCs was decreased (33). ESCC was not an exception to this phenomenon. In a previous study, $\mathrm{CD}{ }^{+}$ESCC cells were isolated using flow cytometry, and further characterization of this population by mRNA profiling suggested that $\mathrm{CD}^{+} 0^{+}$is involved in tumor growth and metastasis, via the dysregulation of the Ets-1/matrix metalloproteinase (MMP) signaling pathway and a change from an epithelial phenotype to a mesenchymal phenotype. The isolated CD90 ${ }^{+}$ESCC cells possessed a higher self-renewal capability and were able to initiate tumor growth, differentiation, metastasis and chemotherapeutic resistance (34). CD44 is a common stem cell marker that has been identified in several types of human cancer, including breast $(31,35)$, gastric $(36)$, prostate (37) and colorectal cancer (38), as well as glioma (39). In addition, CD44 is considered to be a stem cell marker of ESCC (40).

\section{Serum-free suspension culture}

The second method for isolating CSCs from ESCC is to use a serum-free medium suspension culture. In the mid-1960s, serum-free culture was first used to enable the $\mathrm{L}$ cell line to propagate from its low density of inoculum by adding specific nutrients to substitute the serum (41). Serum-free culture was subsequently applied in a cytokine supported stroma-free suspension culture protocols $(42,43)$. To achieve a specific aim, including collecting cytokines or high molecular weight proteins released from cultured cells. Serum-free suspension culture was first applied to isolate human primitive hematopoietic progenitor cells (44) and is widely regarded as an effective method for isolating stem cells or CSCs. However, serum-free suspension culture exhibits limitations, due to the impaired differentiation and increased proliferation abilities of CSCs. It is speculated that the cells in the center of spheres are prone to be senescent. In a sphere, the CSCs are not homogeneous, but hierarchical. The cells closer to the core of the sphere are more differentiated, which is possibly explained by the fact that fewer nutrients reach the core. The cells in the core are prone to differentiation due to a lack of growth factor (45). It is largely accepted that the number of CSCs in the sphere continuously increases, as the cells undergo further passage (46). However, the risk of gene variation increases with each passage. Theoretically, only CSCs can form microspheres; however, not every sphere cell is a CSC. The sphere formation ability can, to a certain extent, reflect the self-renewal ability of CSCs (46). In numerous types of cancer, microsphere cells from the serum-free medium suspension culture have been demonstrated to exhibit stem cell-like characteristics $(47,48)$. Wang et al (49) reported that sphere cells isolated from the ESCC cell lines KYSE 150 and TE1 are more resistant to radiotherapy, when compared with parental cells.

\section{Side population cells}

A third method of CSC isolation is to utilize specific stem cell phenotype determinants, including side population (SP) cells. In 1997, Goodell et al (50) utilized dual-wavelength flow cytometry analysis of murine bone marrow cells stained with 


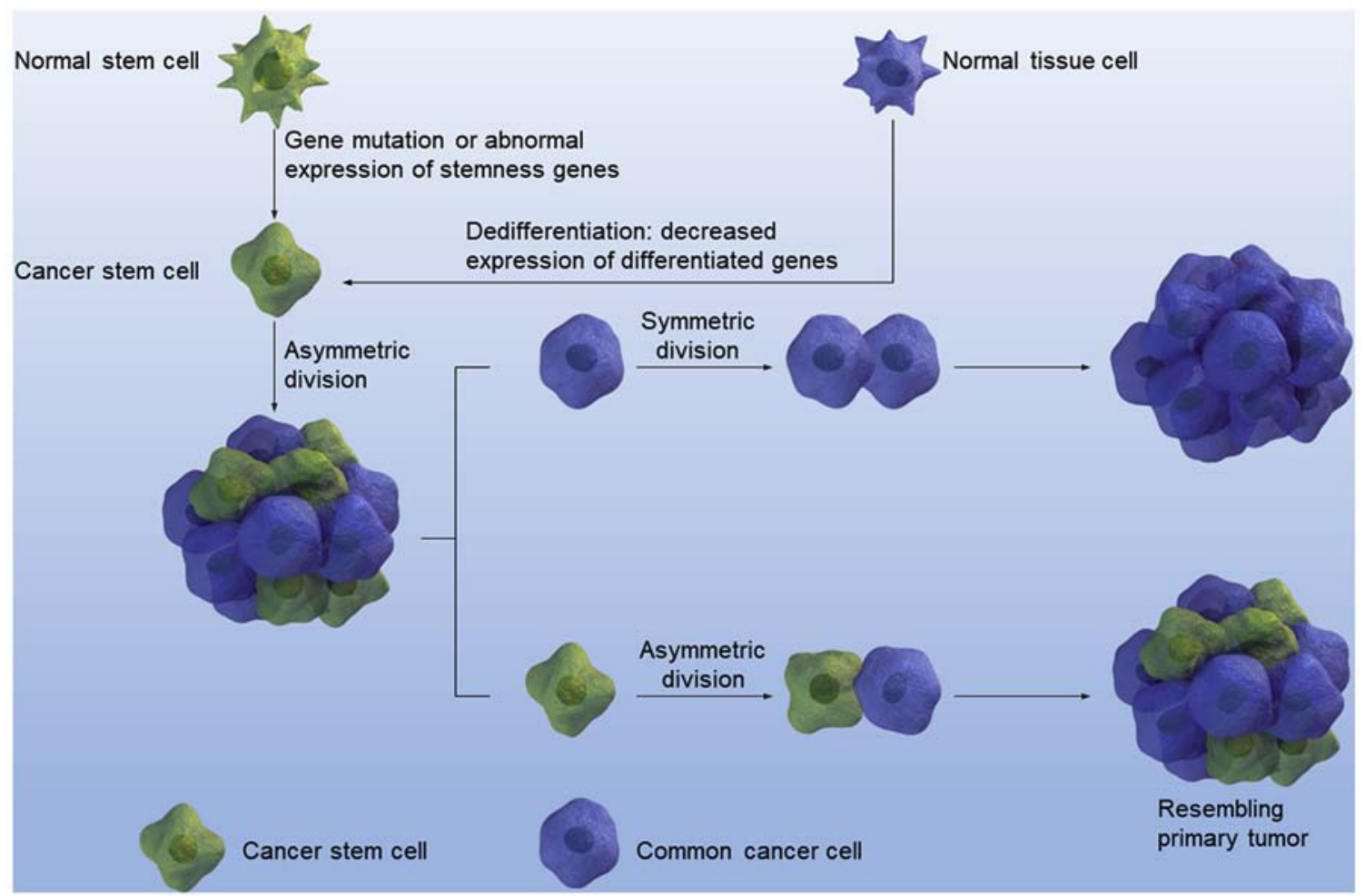

Figure 1. CSCs are derived from mutations in normal stem cells or the dedifferentiation of differentiated cells. Asymmetric division of CSCs can result in an entire tumor that resembles primary tumor. CSC, cancer stem cell.

the fluorescent DNA-binding dye Hoechst 33342 to obtain a small fraction of cells that could efflux the Hoechst dye, defining an extremely small and homogeneous population of cells termed SP cells. These cells are primarily CD34 and lineage marker-negative, highly enriched for long-term culture-initiating cells, which is an indicator of primitive hematopoietic cells, and exhibit the capacity to differentiate into T cells. In addition, SP cells have been demonstrated to have a special type of stem cell phenotype in several normal tissues, including the hematopoietic system (51) and breast epithelium tissue (52). SP cells have also been identified in numerous types of cancer tissue, including leukemia (53), multiple myeloma (54) and breast cancer tissues (55). Furthermore, SP cells can trans-differentiate into other tissue cells. For example, bone marrow-derived SP cells can promote respiratory damage repair in mice in vivo (56). Although SP markers can be viewed as a common stem cell phenotype marker, some debate still exists. ATP binding cassette subfamily $\mathrm{G}$ member 2 (ABCG2) is a membrane receptor, which has a pump function that can remove toxic substances from the cytoplasm, contributing to the phenotype of SP cells. ABCG2 can protect cancer and normal stem cells from X-ray damage. Additionally, ABCG2 has been demonstrated to be a phenotype determinant of SP cells (57). Patrawala et al (58) reported that $\sim 30 \%$ of cultured human cancer cells and xenograft tumors possess a detectable SP. Purified SP cells from U373 glioma cells, MCF7 breast cancer cells and a xenograft prostate tumor were more tumorigenic compared with the corresponding non-SP cells. These SP cells also possess intrinsic stem cell properties, as they generate non-SP cells in vivo, can be further transplanted, and preferentially express specific stemness genes, including Notch-1 and $\beta$-catenin (58).
Since the SP phenotype is primarily mediated by ABCG2, an ATP-binding cassette half-transporter associated with multidrug resistance, the tumorigenicity of $\mathrm{ABCG}^{+}$and ABCG2 cancer cells was investigated. Although SP cells exhibited an increased ABCG2 mRNA expression compared with the non-SP cells, all examined cancer cells and xenograft tumors expressed ABCG2 in a small fraction (0.5-3.0\%) of the cells, highly purified $\mathrm{ABCG} 2^{+}$cancer cells have a very similar tumorigenicity to the ABCG2 cancer cells (58). A mechanistic study has indicated that $\mathrm{ABCG} 2$ expression is associated with proliferation and $\mathrm{ABCG}_{2}{ }^{+}$cancer cells can generate $\mathrm{ABCG} 2$ cells (58). However, ABCG2 cancer cells can also generate $\mathrm{ABCG}^{+}$cells. Furthermore, the ABCG2 cancer cells form more and larger clones in long-term clonal analyses, and the ABCG2 population preferentially expresses several stemness genes (58). These results suggested that, although the SP is enriched with tumorigenic cancer stem-like cells and the ABCG2 expression primarily identifies fast-cycling tumor progenitors, the $\mathrm{ABCG} 2$ population contains primitive cancer stem-like cells. Therefore, $\mathrm{ABCG}^{+}$cancer cells are not equal to SP cells.

Several studies have isolated CSCs from ESCC using SP cells. For example, in 2008, Zhang et al (59) used flow cytometry to serially sort stem-like SP cells, demonstrating that radioresistant cell lines included more SP cells than parent cell lines. Another Chinese research group reported that the number of SP cells was increased in tumor spheres, when compared with adherent cells (60). A previous study by Yue et al (61) demonstrated that stem cell-like SPs in ESCC were a cause of chemotherapy resistance and metastasis. The SP subpopulation was detected using Hoechst 33342 staining in five ESCC cell lines, OE19, OE21, OE33, 
PT1590 and LN1590. Chemotherapy-resistant cell lines were developed following long-term exposure to 5-fluorouracil (5-FU) and cisplatin, and were validated by an analysis of resistance markers, thymidylate synthase and excision repair cross-complement gene 1. While the LN1590 and PT1590 cell lines did not exhibit detectable SP cells, OE19, OE21 and OE33 cells were observed to contain varying levels of SP cells. With the increasing duration of 5-FU or cisplatin therapy, the SP subpopulation substantially emerged in the PT1590 and LN1590 cell lines. SP OE19 cells displayed a significantly higher tumorigenicity compared with non-SP OE19 cells, following the subcutaneous injection of tumor cells in vivo. SP cells isolated from OE19 and OE19 5-FU-resistant cells were subsequently analyzed by an epithelial-to-mesenchymal transition (EMT) polymerase chain reaction array. Notably, the SP fraction of 5-FU resistant OE19 cells led to a marked upregulation of EMT-associated genes, when compared with the SP fraction of OE19 cells (61). These results provided the following evidence: i) The proportion of SP cells is different in ESCC; ii) SP cells exhibit stem cell-like properties and are associated with chemotherapy resistance; and iii) long-term exposure to cytotoxic drug selects for SP cells with an upregulated EMT gene profile, which may be the source of systemic disease relapse. Further investigations are necessary to target these EMT-associated SP cells in ESCC.

\section{ALDH1}

The fourth method for isolating CSCs is the utilization of chemotherapy resistance markers, including ALDH1. ALDH1 has been demonstrated to be a candidate CSC biomarker (62) and has been associated with CSC-like characteristics in numerous types of human cancer (63). Early in 2005, ALDH1 was reported to be expressed at a higher level in $\mathrm{CD} 34^{+}$cells, when compared with differentiated cells, highlighting the important role of ALDH1 in normal hemopoietic stem cell biology (64). Seigel et al (65) reported that $<1 \%$ of retinoblastoma cells exhibit immunoreactivity against the stem cell markers ABCG2 and ALDH1, suggesting that CSCs account for a small fraction of the cells in human cancer. In the following decade, ALDH1 was identified to be overexpressed in various other CSCs, including those of breast (35), lung (66) and pancreatic cancer (67), and can therefore be regarded as a common CSC marker. In ESCC, the expression of ALDH1 protein in the nucleus of ESCCs is associated with lymph node metastasis and a poor survival, suggesting that ALDH1 may be involved in the aggressive behavior of ESCC (68). Although there is no direct evidence to validate that $\mathrm{ALDH}^{+}$cells in ESCC are cancer stem-like cells, several studies hypothesize this to be the case. For example, Song et al (69) demonstrated that the short hairpin RNA (shRNA)-mediated knockdown of yes-associated protein 1 (YAP1) or SRY-box (SOX) 9 in transformed cells attenuates CSC phenotypes in vitro and tumorigenicity in vivo in ESCC. The small-molecule inhibitor of YAP1, verteporfin, blocks ESCC CSC properties in cells with high YAP1 and a high proportion of $\mathrm{ALDH}^{+}$cells (69). Furthermore, Chen et al (70) recently revealed that ALDH1 staining was positively linked to a higher clinical stage, higher loco-regional failure rate, and shorter survival time in ESCC.

\section{Identification of ESCC CSCs}

Following the isolation of a CSC, its identification and verification is imperative. Due to the abundance of isolation methods, different isolation methods have been reported to identify the same CSC with a different cellular phenotype (71). A common method to identify CSCs is to examine the stemness of isolated cells based on three major characteristics: i) Unlimited proliferation ability; ii) self-renewal ability; and iii) strong tumorigenesis (71). Since the concept of CSCs was first introduced, scientists have attempted to isolate CSCs from human ESCC cell lines and tissues.

The three aforementioned CSC characteristics have been applied to investigate the stemness of isolated ESCC cells. Yang et al (72) identified leucine zipper and EF-hand containing transmembrane protein 1 (LETM1) as a marker of cancer stem-like cells and predicted a poor prognosis in ESCC based on the protein expression of LETM1, which was positively correlated with CSC markers in ESCC cell lines. Liu et al (73) reported that Cripto-1 could act as a functional marker of cancer stem-like cells and predict prognosis in patients with ESCC. The suppression of the Cripto- 1 expression by shRNA markedly reduced the expression of stemness- and EMT-associated genes, in addition to their self-renewal capabilities in vitro, and tumorigenicity and metastasis in vivo in ESCC cells. Aldefluor, a fluorescent substrate of aldehyde dehydrogenase, has been used to isolate CSCs; however, it was not as easy to observe the interaction between CSCs and non-CSCs (74). Almanaa et al (75) introduced the attached-cell Aldefluor method to detect CSCs in ESCC cell lines. Almanaa et al (75) also demonstrated a novel method for generating and growing tumor spheres without the growth factor supplements normally used in the medium for their formation. ALDH-1 as a stem cell marker in patients with resectable ESCC, ALDH-1 expression can predict the response or resistance to preoperative chemoradiation (76).

Radioresistance has been identified as a major characteristic of CSCs $(77,78)$. As with common cancer cells, CSCs require telomerase to proliferate (79). Zhang et al (59) attempted to utilize a telomerase-specific oncolytic adenoviral vector carrying apoptotic tumor necrosis factor-related apoptosis-inducing ligand and an E1A gene (Ad/TRAIL-E1) to kill two pairs of parental and $\mathrm{R}$ esophageal carcinoma cell lines (Seg-1, Seg-1R, TE-2 and TE-2R), which had been established via fractionated irradiation. It was observed that the $\mathrm{R}$ esophageal carcinoma cell lines Seg-1R and TE-2R expressed more stem cell markers, including $\beta$-catenin, octamer-binding transcription factor 3/4 (OCT3/4) and $\beta$-integrin, and had a higher proportion of SP cells when compared with the parental Seg- 1 and TE- 2 cell lines. In addition, Seg-1R and TE-2R cells exhibited an increased sensitivity to Ad/TRAIL-E1 compared with parental cells. Increased coxsackie-adenovirus receptor and elevated transgene expression were identified in the $\mathrm{R}$ cells. Ad/TRAIL-E1 resulted in significant tumor growth suppression and longer survival in Seg-1R-bearing mice with no significant toxicity. Chen et al (80) hypothesized that the placental growth factor $(\mathrm{PLGF})^{+}$ESCC TE1 cell line may be CSCs, since significantly higher levels of PLGF and MMP9 were detected in ESCCs with metastasis, when compared with those without, and the expression levels of PLGF and MMP9 were strongly correlated with each other. This resulted 
in the hypothesis that PLGF may activate MMP9 to drive the stemness of ESCC. Tsai et al (81) identified intercellular adhesion molecule 1 (ICAM1) as a potential CSC marker of ESCC using two distinct stemness characteristics of cancer cell lines by a comparative approach that screened for novel CSC membrane protein markers. ICAM1 promotes cancer cell migration and invasion, increases mesenchymal marker expression and attenuates epithelial marker expression. Furthermore, ICAM1 has been reported to contribute to CSC properties, including sphere formation, drug resistance and tumorigenesis in a mouse xenotransplantation model (81). Based on the analysis of ICAM1-regulated proteins, it was revealed that ICAM1 regulates CSC properties, partly through an ICAM1-pituitary tumor-transforming gene 1 protein-interacting protein-p53-DNA methyltransferase 1 pathway. It was also observed that ICAM1 and CD44 could have a compensation effect on maintaining the stemness characteristics of ESCC, suggesting that a combination of multi-targeting therapies should be considered to acquire a more potent therapeutic effect on ESCC CSCs (81). A commonly used CSC marker, ALDH1A1, was identified to define invasive cancer stem-like cells and predict poor prognosis in patients with ESCC (68). CD90 (also termed Thy-1) is a surface glycoprotein of 25-28 $\mathrm{kDa}$, which is expressed on the cytoplasmic membrane of different cell types (82). CD90 ${ }^{+}$ESCC cells have been observed to possess stem cell-like characteristics, and a high tumorigenic and metastatic potential (34). mRNA profiling of $\mathrm{CD} 90^{+} \mathrm{ESCC}$ cells suggested they drive tumor growth and metastasis via the dysregulation of an Ets-1/MMP signaling pathway (34). CD90 ${ }^{+}$ESCC cells possess higher self-renewal activity and are sufficient for tumor growth, differentiation, metastasis and chemotherapeutic resistance. $\mathrm{CD} 90^{+}$tumor-initiating cells were isolated and characterized from ESCC clinical specimens as well as ESCC cell lines. In freshly resected clinical specimens, they represented a rare cell population, the levels of which correlated with strong family histories and lymph node metastasis (34). Although emerging evidence has suggested that bone marrow derived stem cells can cause cancer cells to become CSCs (83), as has been observed in gastric cancer, this was not the case in ESCC. Fan and Lu (84) reported that fusion of human bone hemopoietic stem cells with esophageal carcinoma cells was unable to generate esophageal cancer stem cells.

\section{Signaling pathways dysregulated in ESCC CSCs}

A growing number of signaling pathways, such as Hippo (85) and Wnt (86), have been demonstrated to participate in the regulation of stem cells and CSCs are no exceptions to this. Stem cells are defined by their capacity to undergo unlimited cell division while retaining their stem cell identity, and give rise to more specialized cells with a limited proliferative capacity. Unlimited proliferation, self-renewal and multi-directional differentiation are three major traits closely associated with the stemness of stem cells. During unlimited proliferation, stem cells can retain their stem cell identity; thus, populations of stem cells are self-renewing. On the other hand, proliferation can also generate specialized cells that are differentiated. Numerous stemness pathways can regulate these three major stem-like traits and different signaling pathways such as
WNT/NOTCH Pathway and Sonic Hedgehog Signaling can regulate different stemness characteristics $(87,88)$.

From the signaling pathways dysregulated in ESCC, certain stem-like characteristics have been identified to be associated with CSCs in ESCC. Zhang et al (60) reported that $\mathrm{R}$ cells in ESCC exhibited CSC-like traits and highly expressed $\beta$-catenin. In addition, a cyclooxygenase- 2 inhibitor NS398 had a radiosensitization effect on $\mathrm{R}$ cells via the downregulation of $\beta$-catenin (89). SB525334, a transforming growth factor- $\beta 1$ (TGF- $\beta 1$ ) inhibitor, has been identified to markedly inhibit the migration and invasion of sphere-forming stem-like cells, yet had no effect on their sphere-forming ability, this suggested that TGF- $\beta 1$ may be a biomarker for metastasis in ESCC stem cells; however, was not required for self-renewal (90). TGF- $\beta 1$ can be regarded as a molecular target for the eradication of ESCC stem cell metastasis (90). In addition to its implication in ESCC stem cells, TGF- $\beta 1$ has been reported to regulate the stemness of other CSCs, including those of liver cancer $(91,92)$. TGF- $\beta 1$ can also be induced by a bispecific EpCAM ${ }^{+} \mathrm{CD} 3$ antibody to be released from pre-activated lymphocytes and target $\mathrm{EpCAM}^{+}$retinoblastoma stem cells (93). Although immunotherapy applied to ESCC is not yet effective, we anticipate that in the near future, CSCs may become a highly efficient therapeutic target cell type for immunotherapy in ESCC. The hedgehog (Hh) pathway is involved in CSC maintenance in various types of tumor, and Glioma-associated oncogene homolog 1 (Gli1) is a key mediator of the $\mathrm{Hh}$ pathway $(94,95)$. Yang et al (96) reported Glil to be expressed in $28.3 \%$ of ESCC and to be an indicator of ESCC stem cells, and its expression was correlated with the expression of the stemness genes SOX9 and CD44. Gli1, CD44 and SOX9 were highly expressed in poorly differentiated ESCC cell lines, including TE8 and TE1 cells. Notably, the Gli1 expression was positively associated with distant metastasis, increased microvessel density and the expression of cell cycle regulators, including p21, cyclin D1, cyclin E1 and NF-кB. Fujiwara et al (97) used a NanoCulture ${ }^{\circledR}$ Plate for 3-dimensional cell culture to prepare spheroids from ESCC cells and demonstrated that these spheroids possessed stem cell-like characteristics. Li et al (unpublished data) also utilized serum-free medium supplemented with growth factors to culture ESCC microspheres and observed that these sphere cells displayed a number of CSC-like characteristics. These spheroid cells highly expressed the ALDH1 enzyme, and the mRNA expression of the stem cell-associated genes SOX2, NANOG, OCT3/4 and LIN28 were also elevated (97). Notably, several common stem cell surface markers, including CD44, CD133, CD338 (ABCG2), CD318 (CDCP1) and CD326 (EpCAM), were not observed be elevated. However, Kanamoto et al (98) reported that a single dose of irradiation can induce EMT and CD44 expression, conferring ESCC to acquire cancer stem-like cell properties. miRNAs were also identified to be involved in the signaling pathways of ESCC cancer stem cells. Downregulation of miRNA-644a was suggested to promote ESCC aggressiveness and stem cell-like phenotype via dysregulation of paired like homeodomain 2 (99).

\section{Signaling pathway differences between normal and CSCs}

Until now, stem cells could be classified into several categories, including embryonic or totipotent stem cells, pluripotent 


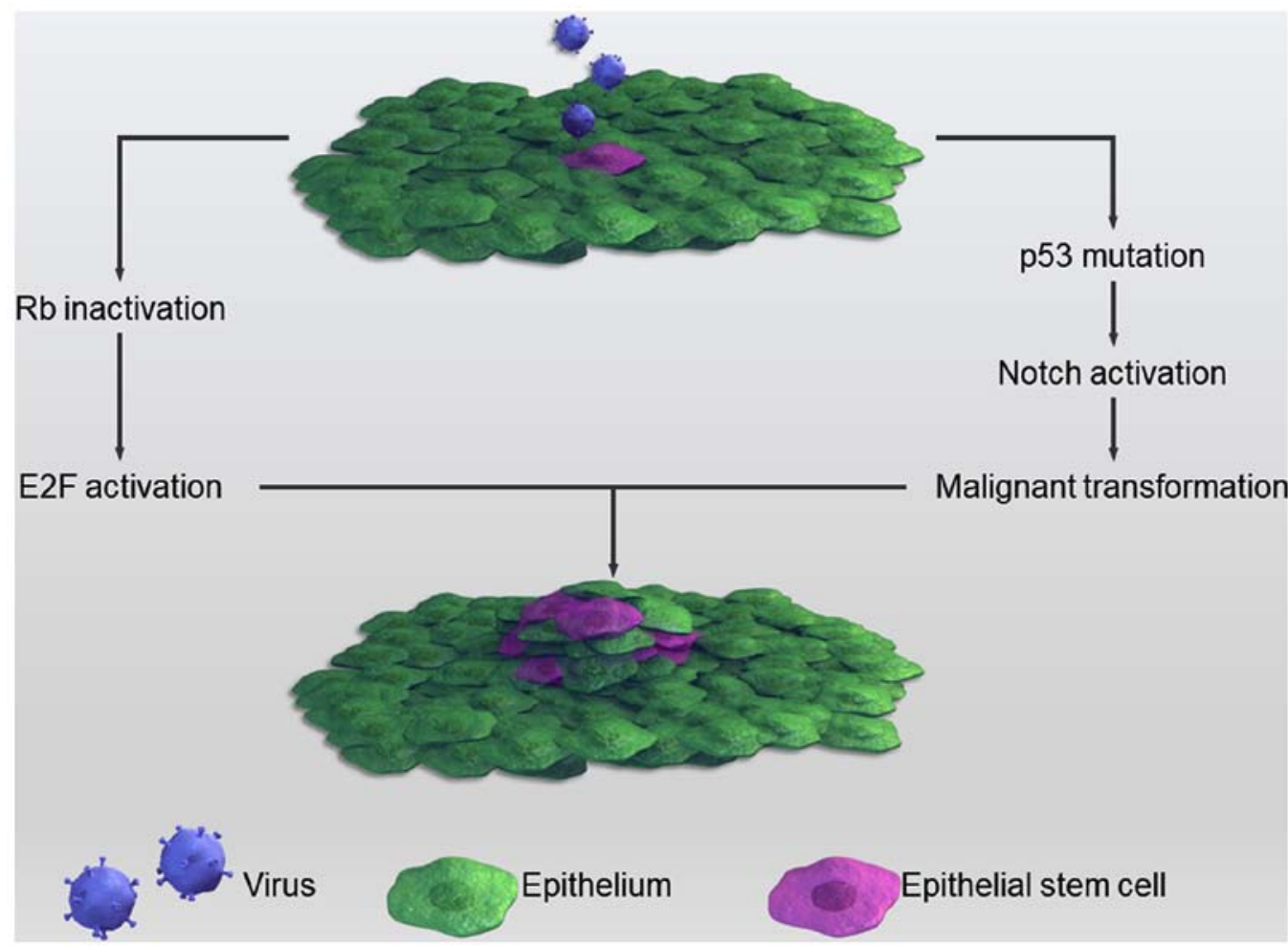

Figure 2. Certain viruses can cause normal stem cells to undergo malignant transformation to cancer stem cells via the inactivation of important suppressors, including p53 and retinoblastoma genes.

stem cells, and tissue-specific stem or precursor cells, thus constituting a hierarchy of stem cells (100). CSCs can also be organized in a hierarchical fashion (101). This theory was initially proposed by Bonnet and Dick (12) in a pioneering study that isolated and identified CSCs in human acute myeloid leukemia. Cancer research then began to focus on stem cells. To a certain extent, a large portion of the CSC research that followed was derived from this initial study. As with normal stem cells, different signaling pathways such as Wnt and Hedgehog signaling participate in the maintenance and regulation of CSCs $(102,103)$. Due to the fact that CSCs are aberrant stem cells, stemness genes are abnormally upregulated or downregulated in CSCs. In addition, CSCs are cancer cells; thus these signaling molecules should also be specific to cancer and dysregulated in cancer cells. Therefore, stemness genes or signaling pathways dysregulated in CSCs should possess two properties: i) The ability to signal the activation of downstream targets that contribute to the maintenance of the three major characteristics of stem cells; and ii) the ability to maintain malignant characteristics (104).

\section{Virus and ESCC stem cells}

It is widely accepted that viruses, including hepatitis B (105), herpes simplex (106), Epstein-Barr viruses (107) and human papillomavirus (HPV) (108), can induce carcinogenesis in specific organs and tissues. In addition, specific viruses have been identified to participate in the formation of CSCs and can target CSCs, and targeting CSCs has been hypothesized to be a treatment method for metastatic cancer due to their high metastatic ability (109). Early in 1999, Hirai et al (110) identified that replication-deficient recombinant adenovirus (Adv) containing the p53 tumor suppressor gene (Adv-p53) can eliminate the human breast CSC products to decrease relapse. In 2007, Eriksson et al (111) reported that oncolytic adenoviruses Ad5/3-Delta24 and Ad5.pk7-Delta24 can selectively kill breast cancer-initiating $\mathrm{CD} 44^{+} \mathrm{CD} 24^{-/ \text {low }}$ cells, and Cho et al (112) isolated and characterized CSCs in MMTV-Wnt-1 murine breast tumors. It has also been demonstrated that the Epstein-Barr virus is an important human carcinogen (113), particularly in nasopharyngeal carcinoma (114). In addition, Satoru et al (115) demonstrated that the principal oncoprotein of Epstein-Barr virus, latent membrane protein 1, promotes tumor cell invasion and metastasis, as well as EMT, and is involved in the formation of CSCs in nasopharyngeal cancer. Furthermore, HPV, which is a common virus closely associated with the occurrence of cervical, oropharyngeal and penile cancer, and head and neck squamous cell carcinoma, was implicated in the occurrence of CSCs (116-119). Cervosphere cells from cervical cancer cell lines, including $\mathrm{SiHa}$, were selectively infected with the HPV virus, since, in confocal images, only cervosphere cells expressed the HPV co-receptor Annexin II on their surface (118). HPV co-receptor Annexin II was less expressed in C-33A cells, an HPV-negative cervical cancer cell line, and in $\mathrm{HaCaT}$ cells, a non-tumorigenic immortalized cell line, compared with HPV-positive cervical cancer cell line and tumorigenic cervical cancer cell line (118). Notably, $\mathrm{HPV}^{+}$oropharyngeal squamous cell carcinomas had an improved prognosis and an increased sensitivity to radiation and chemotherapy compared with their HPV counterparts; differences in the role of the host immune system can partly explain this deviation (118). 
Although the mechanism through which viruses contribute to the stemness of cancers remains to be completely elucidated, several studies have attempted to investigate it. For example, the HPV E6 protein can dysregulate p53, which has been observed to be closely associated with CSCs (120). p53 is 'the guardian of the genome', since genome mutation or instability leads to tumor occurrence (121). Recently, several studies have implied that p53-deficiency confers a CSC-like phenotype $(122,123)$. In cases of cell damage, p53 can lead to cell growth arrest and apoptosis with expression level changes of Nanog and Notch via binding to the promoter region of these two stemness genes. Under normal circumstances, p53 inhibits the Notch pathway; however, when infected with HPV this inhibition is relieved, causing a more proliferative state through the activation of Notch (124). Another common tumor suppressor, the retinoblastoma $(\mathrm{Rb})$ gene, is often mutated in several types of tumors and is associated with CSCs. $\mathrm{HPV}$ can inactivate $\mathrm{Rb}$, thereby causing cancer. Inactivated $\mathrm{Rb}$ predisposes cells to a highly proliferative state through binding to and activating the E2F protein. The E2F protein is a transcriptional factor that promotes cell division (125). The HPV E7 protein forms complexes with $\mathrm{Rb}$, which frees $\mathrm{Rb}$ from E2F and promotes unregulated cell proliferation (126). This process is summarized in Fig. 2.

Numerous viruses, including HPV, herpes simplex virus, cytomegalovirus and Epstein-Barr virus, can infect the esophageal epithelium (127-129). As a result, infection with these viruses may contribute to the pathogenesis of ESCCs. HPV was the first virus to be associated with the pathogenesis of ESCC. In 1990, a study performed in an area of China with a high ESCC-associated morbidity rate revealed that HPV was associated with the carcinogenesis of ESCC, as demonstrated by histological analysis and in situ DNA hybridization (130). Subsequently, a number of studies (131-133) have reinforced this association, although to the best of our knowledge, evidence for HPV as an initiating factor has yet to be established. Furthermore, to the best of our knowledge, the molecular mechanism of HPV infection-associated carcinogenesis in esophagus mucosa and ESCC tissue is unclear. In 2016, Xi et al (134) utilized a lentiviral vector to stably overexpress the high-risk HPV 16, E6 and E7 proteins, and conferred stem-like characteristics on an ESCC cell line, thus providing direct evidence to support HPV participation in the formation of CSCs. However, in ESCC low-morbidity areas, such as Italy, Syrjänen (135) reported that HPV cannot be detected in the ESCC tissue. This result was consistent with those of other studies (136-138), suggesting that, in ESCC low-morbidity areas, HPV is not crucial for esophageal epithelium carcinogenesis. A case-controlled study in Zambia implied that HPV infection was not a risk factor; however, HIV infection and domestic smoke exposure were (139). Consequently, a conclusion can be drawn that HPV alone is insufficient for the occurrence of ESCC, neither is it essential. HPV infection may be a promoting factor in the pathogenesis of ESCC, but not an initiating one.

\section{Conclusion}

In conclusion, CSCs are regarded as target cells that when effectively eradicated have the potential to treat human cancer.
However, there are currently no therapeutics or treatments aimed at eradicating CSCs. Such is the case in ESCC, although CSCs have been identified in ESCC. Due to a lack of early detection methods in ESCC, the disease is frequently diagnosed at the mid or late stages of progression, accompanied by lymph-node metastasis. Systemic therapy, such as targeting CSCs, may ultimately prove crucial for the eradication of this malignant disease. CSCs have been isolated and identified in ESCC for over a decade; however, effective therapies targeting these cells are lacking. Further studies along these lines of investigation are urgently required in order to identify novel and effective therapeutics for ESCC.

\section{Acknowledgements}

Not applicable.

\section{Funding}

The present study was funded by grants from the Natural Science Funding of China (grant no. 71473073) and the Department of Science and Technology of Hubei province (grant nos. 2015CFB470 and 2015CFC773).

\section{Availability of data and materials}

All data generated or analyzed during the present study are included in this published article.

\section{Authors' contributions}

QW, ZW, CB and WL wrote the manuscript. HH, YS and ZC contributed to the review of the literature. HZ and ZN contributed to the concept of the manuscript. All authors read and approved the final manuscript.

\section{Ethics approval and consent to participate}

Not applicable.

\section{Patient consent for publication}

Not applicable.

\section{Competing interests}

The authors declare that they have no competing interests.

\section{References}

1. Chen W, Zheng R, Baade PD, Zhang S, Zeng H, Bray F, Jemal A, Yu XQ and He J: Cancer statistics in China 2015. Ca Cancer J Clin 66: 115-132, 2016.

2. Siegel RL, Miller KD and Jemal A: Cancer statistics, 2018. CA Cancer J Clin 68: 7-30, 2018.

3. Huang Y, Qu S, Zhu G, Wang F, Liu R, Shen X, Viola D, Elisei R, Puxeddu E, Fugazzola L, et al: BRAF V600E mutation-assisted risk stratification of solitary intrathyroidal papillary thyroid cancer for precision treatment. J Natl Cancer Inst 110: 362-370, 2018.

4. Leonard KL and Wazer DE: Genomic assays and individualized treatment of ductal carcinoma in situ in the era of value-based cancer care. J Clin Oncol 34: 3953-2955, 2016. 
5. Dos Santos M, Brachet PE, Chevreau C and Joly F: Impact of targeted therapies in metastatic renal cell carcinoma on patient-reported outcomes: Methodology of clinical trials and clinical benefit. Cancer Treat Rev 53: 53-60, 2017.

6. Chen DS and Mellman I: Elements of cancer immunity and the cancer-immune set point. Nature 541: 321-330, 2017.

7. Başaran GA, Twelves C, Diéras V, Cortés J and Awada A: Ongoing unmet needs in treating estrogen receptor-positive/HER2-negative metastatic breast cancer. Cancer Treat Rev 63: 144-155, 2018.

8. Bourke L, Kirkbride P, Hooper R, Rosario AJ, Chico TJ and Rosario DJ: Endocrine therapy in prostate cancer: Time for reappraisal of risks, benefits and cost-effectiveness? Br J Cancer 108 9-13, 2013

9. Han SH, Kim JW, Kim M, Kim JH, Lee KW, Kim BH, Oh HK, Kim DW, Kang SB, Kim H and Shin E: Prognostic implication of ABC transporters and cancer stem cell markers in patients with stage III colon cancer receiving adjuvant FOLFOX-4 chemotherapy. Oncol Lett 17: 5572-5580, 2019.

10. Xu PP, Fu D, Li JY, Hu JD, Wang X, Zhou JF, Yu H, Zhao X, Huang YH, Jiang L, et al: Anthracycline dose optimisation in patients with diffuse large B-cell lymphoma: A multicentre, phase 3, randomised, controlled trial. Lancet Haematol 6: e328-e337, 2019.

11. Rous P: The relations of embryonic tissue and tumor in mixed grafts. J Exp Med 13: 239-247, 1911.

12. Bonnet D and Dick JE: Human acute myeloid leukemia is organized as a hierarchy that originates from a primitive hematopoietic cell. Nat Med 3: 730-737, 1997.

13. ZD: Carcinogenesis. Medicine (ed. Zaridze, D.G.): 1-567, 2004.

14. Dick JE and Tsvee L: Biology of normal and acute myeloid leukemia stem cells. Int J Hematol 82: 389-396, 2005.

15. Wright MH, Calcagno AM, Salcido CD, Carlson MD Ambudkar SV and Lyuba V: Brca1 breast tumors contain distinct CD44+/CD24- and CD133+ cells with cancer stem cell characteristics. Breast Cancer Res 10: R10, 2008.

16. Singh SK, Hawkins C, Clarke ID, Squire JA, Bayani J, Hide T, Henkelman RM, Cusimano MD and Dirks PB: Identification of human brain tumour initiating cells. Nature 432: 396-401, 2004

17. Collins AT, Berry PA, Hyde C, Stower MJ and Maitland NJ: Prospective identification of tumorigenic prostate cancer stem cells. Cancer Res 65: 10946-10951, 2005.

18. Odoux C, Fohrer H, Hoppo T, Guzik L, Stolz DB, Lewis DW, Gollin SM, Gamblin TC, Geller DA and Lagasse E: A stochastic model for cancer stem cell origin in metastatic colon cancer Cancer Research 68: 6932-6941, 2008.

19. Vermeulen L, Todaro M, de Sousa Mello F, Sprick MR, Kemper K Perez Alea M, Richel DJ, Stassi G and Medema JP: Single-cel cloning of colon cancer stem cells reveals a multi-lineage differentiation capacity. Proc Natl Acad Sci USA 105: 13427-13432, 2008.

20. Zhang H, Hao C, Wang H, Shang H and Li Z: Carboxypeptidase A4 promotes proliferation and stem cell characteristics of hepatocellular carcinoma. Int J Exp Pathol 100: 133-138, 2019.

21. Li X, Zhang Y, Ding J, Wang M, Li N, Yang H, Wang K, Wang D, Lin PP, Li M, et al: Clinical significance of detecting CSF-derived tumor cells in breast cancer patients with leptomeningeal metastasis. Oncotarget 9: 2705-2714, 2017.

22. Lin Y, Totsuka Y, He Y, Kikuchi S, Qiao Y, Ueda J, Wei W, Inoue $\mathrm{M}$ and Tanaka $\mathrm{H}$ : Epidemiology of esophageal cancer in Japan and China. J Epidemiol 23: 233-242, 2013.

23. Ferlay J, Soerjomataram I, Dikshit R, Eser S, Mathers C, Rebelo M, Parkin DM, Forman D and Bray F: Cancer incidence and mortality worldwide: Sources, methods and major patterns in GLOBOCAN 2012. Int J Cancer 136: E359-E386, 2015.

24. Lao-Sirieix P and Fitzgerald RC: Screening for oesophageal cancer. Nat Rev Clin Oncol 9: 278-287, 2012

25. Pennathur A, Gibson MK, Jobe BA and Luketich JD: Oesophageal carcinoma. Lancet 381: 400-412, 2013.

26. Chen M, Liu P, Chen Y, Chen Z, Shen M, Liu X, Li X, Lin Y, Yang $\mathrm{R}, \mathrm{Ni} \mathrm{W}$, et al: Primary tumor regression patterns in esophageal squamous cell cancer treated with definitive chemoradiotherapy and implications for surveillance schemes. Cancer Manag Res 11: 3361-3369, 2019.

27. Vira D, Basak SK, Veena MS, Wang MB, Batra RK and Srivatsan ES Cancer stem cells, microRNAs, and therapeutic strategies including natural products. Cancer Metastasis Rev 31: 733-751, 2012.

28. Fu W, Lei C, Yu Y, Liu S, Li T, Lin F, Fan X, Shen Y, Ding M, Tang Y, et al: EGFR/Notch antagonists enhance the response to inhibitors of the PI3K-Akt pathway by decreasing tumour-initiating cell frequency. Clin Cancer Res 25: 2835-2847, 2019.
29. Jia ZF, Wu YH, Cao DH, Cao XY, Jiang J and Zhou BS: Polymorphisms of cancer stem cell marker gene CD133 are associated with susceptibility and prognosis of gastric cancer. Future Oncol 13: 979-989, 2017.

30. Kalantari E, Asgari M, Nikpanah S, Salarieh N, Lari MH and Madjd Z: Co-expression of putative cancer stem cell markers CD44 and CD133 in prostate carcinomas. Pathol Oncol Res 23: 793-802, 2017

31. Al-Hajj M, Wicha MS, Benito-Hernandez A, Morrison SJ and Clarke MF: Prospective identification of tumorigenic breast cancer cells. Proc Natl Acad Sci USA 100: 3983-3988, 2003.

32. Yan Y, Zuo X and Wei D: Concise review: Emerging role of CD44 in cancer stem cells: A promising biomarker and therapeutic target. Stem Cells Transl Med 4: 1033-1043, 2015.

33. Liou GY: CD133 as a regulator of cancer metastasis through the cancer stem cells. Int J Biochem Cell Biol 106: 1-7, 2019.

34. Tang KH, Dai YD, Tong M, Chan YP, Kwan PS, Fu L, Qin YR, Tsao SW, Lung HL, Lung ML, et al: A CD90(+) tumor-initiating cell population with an aggressive signature and metastatic capacity in esophageal cancer. Cancer Res 73: 2322-2332, 2013.

35. Moreira MP, da Conceição Braga L and Silva LM: STAT3 as a promising chemoresistance biomarker associated with the $\mathrm{CD}^{44+/ \text { high }} / \mathrm{CD} 24^{-/ \text {low }} / \mathrm{ALDH}^{+} \mathrm{BCSCs}$-like subset of the triple-negative breast cancer (TNBC) cell line. Exp Cell Res 363: 283-290, 2018

36. Nguyen PH, Giraud J, Staedel C, Chambonnier L, Dubus P, Chevret E, Bœuf H, Gauthereau X, Rousseau B, Fevre M, et al: All-trans retinoic acid targets gastric cancer stem cells and inhibits patient-derived gastric carcinoma tumor growth. Oncogene 35: 5619-5628, 2016.

37. Erb HHH, Guggenberger F, Santer FR and Culig Z: Interleukin- 4 induces a CD $44_{\text {high }} / C D 49 b_{\text {high }}$ PC 3 subpopulation with tumor-initiating characteristics. J Cell Biochem 119: 4103-4112, 2018

38. Ogawa T, Hirohashi Y, Murai A, Nishidate T, Okita K, Wang L, Ikehara Y, Satoyoshi T, Usui A, Kubo T, et al: ST6GALNAC1 plays important roles in enhancing cancer stem phenotypes of colorectal cancer via the Akt pathway. Oncotarget 8: 112550-112564, 2017.

39. Wang HH, Liao CC, Chow NH, Huang LL, Chuang JI, Wei KC and Shin JW: Whether CD44 is an applicable marker for glioma stem cells. Am J Transl Res 9: 4785-4806, 2017.

40. Zhao JS, Li WJ, Ge D, Zhang PJ, Li JJ, Lu CL, Ji XD, Guan DX, $\mathrm{Gao} \mathrm{H}, \mathrm{Xu} \mathrm{LY}$, et al: Tumor initiating cells in esophageal squamous cell carcinomas express high levels of CD44. PLoS One 6: e21419, 2011.

41. Matsuya Y: A serum-free culture medium for the minor inoculum of L line cells. Tohoku J Exp Med 86: 1-8, 1965.

42. Haylock DN, To LB, Dowse TL, Juttner CA and Simmons PJ: Ex vivo expansion and maturation of peripheral blood CD34+ cells into the myeloid lineage. Blood 80: 1405-1412, 1992

43. Petzer AL, Zandstra PW, Piret JM and Eaves CJ: Differential cytokine effects on primitive (CD34+CD38-) human hematopoietic cells: Novel responses to Flt3-ligand and thrombopoietin. J Exp Med 183: 2551-2558, 1996.

44. Möbest D, Goan SR, Junghahn I, Winkler J, Fichtner I, Hermann M, Becker M, de Lima-Hahn E and Henschler R: Differential kinetics of primitive hematopoietic cells assayed in vitro and in vivo during serum-free suspension culture of CD34+ blood progenitor cells. Stem Cells 17: 152-161, 1999.

45. Jimenez-Pascual A, Hale JS, Kordowski A, Pugh J, Silver DJ, Bayik D, Roversi G, Alban TJ, Rao S, Chen R, et al: ADAMDEC1 maintains a growth factor signaling loop in cancer stem cells. Cancer Discov: pii: CD-18-1308, 2019.

46. Abbaszadegan MR, Bagheri V, Razavi MS, Momtazi AA, Sahebkar A and Gholamin M: Isolation, identification and characterization of cancer stem cells: A review. J Cell Physiol 232: 2008-2018, 2017.

47. Xiao G, Li X, Li G, Zhang B, Xu C, Qin S, Du N, Wang J, Tang SC, Zhang J, et al: MiR-129 blocks estrogen induction of NOTCH signaling activity in breast cancer stem-like cells. Oncotarget 8: 103261-103273, 2017.

48. Trisciuoglio D, Tupone MG, Desideri M, Di Martile M, Gabellini C, Buglioni S, Pallocca M, Alessandrini G, D'Aguanno $S$ and Del Bufalo D: BCL-X $X_{L}$ overexpression promotes tumor progression-associated properties. Cell Death Dis 8: 3216, 2017.

49. Wang JL, Yu JP, Sun ZQ and Sun SP: Radiobiological characteristics of cancer stem cells from esophageal cancer cell lines. World J Gastroenterol 20: 18296-18305, 2014. 
50. Goodell MA, Rosenzweig M, Kim H, Marks DF, DeMaria M, Paradis G, Grupp SA, Sieff CA, Mulligan RC and Johnson RP: Dye efflux studies suggest that hematopoietic stem cells expressing low or undetectable levels of CD34 antigen exist in multiple species. Nat Med 3: 1337-1345, 1997.

51. Parmar K, Sauk-Schubert C, Burdick D, Handley M and Mauch P: Sca+CD34- murine side population cells are highly enriched for primitive stem cells. Exp Hematol 31: 244-250, 2003.

52. Alvi AJ, Clayton H, Joshi C, Enver T, Ashworth A, Vivanco Md, Dale TC and Smalley MJ: Functional and molecular characterisation of mammary side population cells. Breast Cancer Research 5: R1-R8, 2002.

53. Gross E, L'Faqihiolive FE, Ysebaert L, Brassac M, Struski S, Kheirallah S, Fournié JJ, Laurent G and Quillet-Mary A: B-chronic lymphocytic leukemia chemoresistance involves innate and acquired leukemic side population cells. Leukemia 24 $1885-1892,2010$

54. Du J, Liu S, He J, Liu X, Qu Y, Yan W, Fan J, Li R, Xi H, $\mathrm{Fu}$ W, et al: MicroRNA-451 regulates stemness of side population cells via PI3K/Akt/mTOR signaling pathway in multiple myeloma. Oncotarget 6: 14993-15007, 2015.

55. Britton KM, Kirby JA, Lennard TW and Meeson AP: Cancer stem cells and side population cells in breast cancer and metastasis. Cancers 3: 2106-2130, 2011.

56. Macpherson H, Keir P, Webb S, Samuel K, Boyle S, Bickmore W, Forrester L and Dorin J: Bone marrow-derived SP cells can contribute to the respiratory tract of mice in vivo. J Cell Sci 118 2441-2450, 2005.

57. Shimoda M, Ota M and Okada Y: Isolation of cancer stem cells by side population method. Methods Mol Biol 1692: 49-59, 2018

58. Patrawala L, Calhoun T, Schneider-Broussard R, Zhou J, Claypool K and Tang DG: Side population is enriched in tumorigenic, stem-like cancer cells, whereas ABCG2+ and ABCG2-cancer cells are similarly tumorigenic. Cancer Res 65 : 6207-6019, 2005.

59. Zhang X, Komaki R, Wang L, Fang B and Chang JY: Treatment of radioresistant stem-like esophageal cancer cells by an apoptotic gene-armed, telomerase-specific oncolytic adenovirus. Clin Cancer Res 14: 2813-2823, 2008.

60. Zhang G, Ma L, Xie YK, Miao XB and Jin C: Esophageal cancer tumorspheres involve cancer stem-like populations with elevated aldehyde dehydrogenase enzymatic activity. Mol Med Rep 6 : 519-524, 2012.

61. Yue Z, Qi B, Bettina S, Zhao L, Mysliwietz J, Ellwart J, Renner A, Hirner H, Niess H, Camaj P, et al: Stem cell-like side populations in esophageal cancer: A source of chemotherapy resistance and metastases. Stem Cells Dev 23: 180-192, 2014.

62. Chen J, Xia Q, Jiang B, Chang W, Yuan W, Ma Z, Liu Z and Shu X: Prognostic value of cancer stem cell marker ALDH1 expression in colorectal cancer: A systematic review and meta-analysis. PLoS One 10: e0145164, 2015.

63. Zhou Y, Wang Y, Ju X, Lan J, Zou H, Li S, Qi Y, Jia W, Hu J, Liang W, et al: Clinicopathological significance of ALDH1A1 in lung, colorectal, and breast cancers: A meta-analysis. Biomark Med 9: 777-790, 2015.

64. Ferrell CM, Dorsam ST, Ohta H, Humphries RK, Derynck MK, Haqq C, Largman C and Lawrence HJ: Activation of stem-cel specific genes by HOXA9 and HOXA10 homeodomain proteins in CD34+ human cord blood cells. Stem Cells 23: 644-655, 2010

65. Seigel GM, Campbell LM, Narayan M and Gonzalez-Fernandez F Cancer stem cell characteristics in retinoblastoma. Mol Vis 11: 729-737, 2005

66. Macdonagh L, Gallagher MF, Ffrench B, Gasch C, Breen E, Gray SG, Nicholson S, Leonard N, Ryan R, Young V, et al: Targeting the cancer stem cell marker, aldehyde dehydrogenase 1 , to circumvent cisplatin resistance in NSCLC. Oncotarget 8 : 72544-72563, 2017.

67. Fu Z, Chen C, Zhou Q, Wang Y, Zhao Y, Zhao X, Li W, Zheng S, Ye H, Wang L, et al: LncRNA HOTTIP modulates cancer stem cell properties in human pancreatic cancer by regulating HOXA9. Cancer Lett 410: 68-81, 2017.

68. Ji Y, Li X, Li Y, Zhong Y, Cao J, Xu R, Wang J, Zhou F, Li X, Yu D, et al: Aldehyde dehydrogenase-1 expression predicts unfavorable outcomes in patients with esophageal squamous cell carcinoma. Anticancer Res 36: 343-349, 2016.

69. Song S, Ajani JA, Honjo S, Maru DM, Chen Q, Scott AW, Heallen TR, Xiao L, Hofstetter WL, Weston B, et al: Hippo coactivator YAP1 upregulates SOX9 and endows esophageal cancer cells with stem-like properties. Cancer Res 74: 4170-4182, 2014.
70. Chen MF, Chen PT, Lu MS and Chen WC: Role of ALDH1 in the prognosis of esophageal cancer and its relationship with tumor microenvironment. Mol Carcinog 57: 78-88, 2018.

71. Akbarzadeh M, Maroufi NF, Tazehkand AP, Akbarzadeh M, Bastani S, Safdari R, Farzane A, Fattahi A, Nejabati HR, Nouri M and Samadi N: Current approaches in identification and isolation of cancer stem cells. J Cell Physiol: Feb 11, 2019 doi: 10.1002/jcp.28271 (Epub ahead of print).

72. Yang Z, Ni W, Cui C, Qi W, Piao L and Xuan Y: Identification of LETM1 as a marker of cancer stem-like cells and predictor of poor prognosis in esophageal squamous cell carcinoma. Hum Pathol 81: 148-156, 2018.

73. Liu Q, Cui X, Yu X, Bian BS, Qian F, Hu XG, Ji CD, Yang L, Ren Y, Cui W, et al: Cripto-1 acts as a functional marker of cancer stem-like cells and predicts prognosis of the patients in esophageal squamous cell carcinoma. Mol Cancer 16: 81, 2017.

74. Cabrera MC, Hollingsworth RE and Hurt EM: Cancer stem cell plasticity and tumor hierarchy. World J Stem Cells 7: 27-36, 2015.

75. Almanaa TN, Geusz ME and Jamasbi RJ: A new method for identifying stem-like cells in esophageal cancer cell lines. J Cancer 4: 536-548, 2013.

76. Ajani JA, Wang X, Song S, Suzuki A, Taketa T, Sudo K, Wadhwa R, Hofstetter WL, Komaki R, Maru DM, et al: ALDH-1 expression levels predict response or resistance to preoperative chemoradiation in resectable esophageal cancer patients. Mol Oncol 8: 142-149, 2014.

77. Chang L, Graham P, Hao J, Ni J, Deng J, Bucci J, Malouf D, Gillatt D and Li Y: Cancer stem cells and signaling pathways in radioresistance. Oncotarget 7: 11002-11017, 2016.

78. Lynam-Lennon N, Heavey S, Sommerville G, Bibby BA, Ffrench B, Quinn J, Gasch C, O'Leary JJ, Gallagher MF, Reynolds JV and Maher SG: MicroRNA-17 is downregulated in esophageal adenocarcinoma cancer stem-like cells and promotes a radioresistant phenotype. Oncotarget 8 : 11400-11413, 2017.

79. Chen KH, Guo Y, Li L, Qu S, Zhao W, Lu QT, Mo QY, Yu BB, Zhou L, Lin GX, et al: Cancer stem cell-like characteristics and telomerase activity of the nasopharyngeal carcinoma radioresistant cell line CNE-2R. Cancer Med 7: 4755-4764, 2018.

80. Chen Y, Jiang T, Mao A and Xu J: Esophageal cancer stem cells express PLGF to increase cancer invasion through MMP9 activation. Tumour Biol 35: 12749-12755, 2014.

81. Tsai ST, Wang PJ, Liou NJ, Lin PS, Chen CH and Chang WC: ICAM1 is a potential cancer stem cell marker of esophageal squamous cell carcinoma. PLoS One 10: e0142834, 2015.

82. Sauzay C, Voutetakis K, Chatziioannou A, Chevet E and Avril T: CD90/Thy-1, a cancer-associated cell surface signaling molecule. Front Cell Dev Biol 7: 66, 2019.

83. Ji N, Yu JW, Ni XC, Wu JG, Wang SL and Jiang BJ: Bone marrow-derived mesenchymal stem cells increase drug resistance in CD133-expressing gastric cancer cells by regulating the PI3K/AKT pathway. Tumor Biol 37: 14637-14651, 2016.

84. Fan $\mathrm{H}$ and Lu S: Fusion of human bone hemopoietic stem cell with esophageal carcinoma cells didn't generate esophageal cancer stem cell. Neoplasma 61: 540-545, 2014.

85. Mo JS, Park HW and Guan KL: The Hippo signaling pathway in stem cell biology and cancer. EMBO Rep 15: 642-656, 2014.

86. Sharon N, Vanderhooft J, Straubhaar J, Mueller J, Chawla R, Zhou Q, Engquist EN, Trapnell C, Gifford DK and Melton DA: Wnt signaling separates the progenitor and endocrine compartments during pancreas development. Cell Rep 27: 2281-2291.e5, 2019.

87. Ma L, Wang Y, Hui Y, Du Y, Chen Z, Feng H, Zhang S, Li N, Song J, Fang Y, et al: WNT/NOTCH pathway is essential for the maintenance and expansion of human MGE progenitors. Stem Cell Reports 12: 934-949, 2019.

88. Huynh DL, Koh H, Chandimali N, Zhang JJ, Kim N, Kang TY, Ghosh M, Gera M, Park YH, Kwon T and Jeong DK: BRM270 inhibits the proliferation of CD44 positive pancreatic ductal adenocarcinoma cells via downregulation of sonic hedgehog signaling. Evid Based Complement Alternat Med 2019: 8620469, 2019.

89. Che SM, Zhang XZ, Liu XL, Chen X and Hou L: The radiosensitization effect of NS398 on esophageal cancer stem cell-like radioresistant cells. Dis Esophagus 24: 265-273, 2011.

90. Yue D, Zhang Z, Li J, Chen X, Ping Y, Liu S, Shi X, Li L, Wang L, Huang L, et al: Transforming growth factor-beta1 promotes the migration and invasion of sphere-forming stem-like cell subpopulations in esophageal cancer. Exp Cell Res 336: 141-149, 2015. 
91. Ding W, Mouzaki M, You H, Laird JC, Mato J, Lu SC and Rountree CB: CD133+ liver cancer stem cells from methionine adenosyl transferase 1A-deficient mice demonstrate resistance to transforming growth factor (TGF)-beta-induced apoptosis. Hepatology 49: 1277-1286, 2009.

92. Mima K, Okabe H, Ishimoto T, Hayashi H, Nakagawa $\mathrm{S}$, Kuroki H, Watanabe M, Beppu T, Tamada M, Nagano O, et al: CD44s regulates the TGF- $\beta$-mediated mesenchymal phenotype and is associated with poor prognosis in patients with hepatocellular carcinoma. Cancer Res 72: 3414-3423, 2012.

93. Mitra M, Kandalam M, Harilal A, Verma RS, Krishnan UM, Swaminathan S and Krishnakumar S: EpCAM is a putative stem marker in retinoblastoma and an effective target for T-cell-mediated immunotherapy. Mol Vis 18: 290-308, 2012.

94. Zhang M, Tan S, Yu D, Zhao Z, Zhang B, Zhang P, Lv C, Zhou Q and Cao Z: Triptonide inhibits lung cancer cell tumorigenicity by selectively attenuating the Shh-Glil signaling pathway. Toxicol Appl Pharmacol 365: 1-8, 2019.

95. Arai MA, Ochi F, Makita Y, Chiba T, Higashi K, Suganami A, Tamura Y, Toida T, Iwama A, Sadhu SK, et al: GLI1 inhibitors identified by target protein oriented natural products isolation (TPO-NAPI) with hedgehog inhibition. ACS Chem Biol 13: 2551-2559, 2018

96. Yang Z, Cui Y, Ni W, Kim S and Xuan Y: Gli1, a potential regulator of esophageal cancer stem cell, is identified as an independent adverse prognostic factor in esophageal squamous cell carcinoma. J Cancer Res Clin Oncol 143: 243-254, 2017

97. Fujiwara D, Kato K, Nohara S, Iwanuma Y and Kajiyama Y: The usefulness of three-dimensional cell culture in induction of cancer stem cells from esophageal squamous cell carcinoma cell lines. Biochem Biophys Res Commun 434: 773-778, 2013.

98. Kanamoto A, Ninomiya I, Harada S, Tsukada T, Okamoto K, Nakanuma S, Sakai S, Makino I, Kinoshita J, Hayashi H, et al: Valproic acid inhibits irradiation-induced epithelial-mesenchymal transition and stem cell-like characteristics in esophageal squamous cell carcinoma. Int J Oncol 49: 1859-1869, 2016.

99. Zhang JX, Chen ZH, Xu Y, Chen JW, Weng HW, Yun M, Zheng ZS, Chen C, Wu BL, Li EM, et al: Downregulation of MicroRNA-644a promotes esophageal squamous cell carcinoma aggressiveness and stem-cell-like phenotype via dysregulation of PITX2. Clin Cancer Res 23: 298-310, 2017.

100. De Luca M, Aiuti A, Cossu G, Parmar M, Pellegrini G and Robey PG: Advances in stem cell research and therapeutic development. Nat Cell Biol 21: 801-811, 2019.

101. Reya T, Morrison SJ, Clarke MF and Weissman IL: Stem cells, cancer, and cancer stem cells. Nature 414: 105-111, 2001.

102. de Sousa EM, Vermeulen L, Richel D and Medema JP: Targeting Wnt signaling in colon cancer stem cells. Clin Cancer Res 17 647-653, 2011 .

103. Merchant AA and William M: Targeting Hedgehog-a cancer stem cell pathway. Clin Cancer Res 16: 3130-3140, 2010.

104. Galoczova M, Coates P and Vojtesek B: STAT3, stem cells, cancer stem cells and p63. Cell Mol Biol Lett 23: 12, 2018.

105. Fu J and Wang $\mathrm{H}$ : Precision diagnosis and treatment of liver cancer in China. Cancer Lett 412: 283-288, 2017.

106. Irwin CR, Hitt MM and Evans DH: Targeting nucleotide biosynthesis: A strategy for improving the oncolytic potential of DNA viruses. Front Oncol 7: 229, 2017.

107. Pandey S and Robertson ES: Oncogenic Epstein-Barr virus recruits $\mathrm{Nm} 23-\mathrm{H} 1$ to regulate chromatin modifiers. Lab Invest 98: 258-268, 2018.

108. Lin TA, Garden AS, Elhalawani H, Elgohari B, Jethanandani A, Ng SP, Mohamed AS, Frank SJ, Glisson BS, Debnam JM, et al: Radiographic retropharyngeal lymph node involvement in human papillomavirus-associated oropharyngeal carcinoma: Patterns of involvement and impact on patient outcomes. Cancer 125: 1536-1546, 2019

109. Wang D, Plukker JTM and Coppes RP: Cancer stem cells with increased metastatic potential as a therapeutic target for esophageal cancer. Semin Cancer Biol 44: 60-66, 2017.

110. Hirai M, Kelsey LS, Vaillancourt M, Maneval DC, Watanabe T and Talmadge JE: Purging of human breast cancer cells from stem cell products with an adenovirus containing p53. Cancer Gene Ther 7: 197-206, 2000

111. Eriksson M, Guse K, Bauerschmitz G, Virkkunen P, Tarkkanen M, Tanner M, Hakkarainen T, Kanerva A, Desmond RA, Pesonen S and Hemminki A: Oncolytic adenoviruses kill breast cancer initiating CD44+CD24-/low cells. Mol Ther 15: 2088-2093, 2007.
112. Cho RW, Wang X, Diehn M, Shedden K, Chen GY, Sherlock G, Gurney A, Lewicki J and Clarke MF: Isolation and molecular characterization of cancer stem cells in MMTV-Wnt-1 murine breast tumors. Stem Cells 26: 364-371, 2010.

113. Mui UN, Haley CT and Tyring SK: Viral oncology: Molecular biology and pathogenesis. J Clin Med 6: pii: 111, 2017.

114. Ali SM, Ross JS and Wang K: Reply to Genomic profiles of nasopharyngeal carcinoma: The importance of histological subtyping and Epstein-Barr virus in situ assays. Cancer 124: 435-436, 2018

115. Satoru K, Naohiro W, Masamichi M, Zen Y, Endo K, Murono S, Sugimoto H, Yamaoka S, Pagano JS and Yoshizaki T: Epstein-Barr virus latent membrane protein 1 induces cancer stem/progenitor-like cells in nasopharyngeal epithelial cell lines. J Virol 85: 11255-11264, 2011

116. Chris C, Figueroa JA, Leonardo M, Colombo M, Summers G, Figueroa A, Aulakh A, Konala V, Verma R, Riaz J, et al: The role of human papilloma virus (HPV) infection in non-anogenital cancer and the promise of immunotherapy: A review. Int Rev Immunol 33: 383-401, 2014

117. Swanson MS, Kokot N and Sinha UK: The role of HPV in head and neck cancer stem cell formation and tumorigenesis. Cancers (Basel) 8: pii: E24, 2016.

118. Ortiz-Sánchez E, Santiago-López L, Cruz-Domínguez VB, Toledo-Guzmán ME, Hernández-Cueto D, Muñiz-Hernández S, Garrido E, Cantú De León D and García-Carrancá A: Characterization of cervical cancer stem cell-like cells: Phenotyping, stemness, and human papilloma virus co-receptor expression. Oncotarget 7: 31943-31954, 2016.

119. Lanfredini S, Olivero C, Borgogna C, Calati F, Powell K, Davies KJ, De Andrea M, Harries S, Tang HKC, Pfister H, et al: HPV8 field cancerization in a transgenic mouse model is due to Lrig1+ keratinocyte stem cell expansion. J Invest Dermatol 137: 2208-2216, 2017.

120. Zhang M, Kumar B, Piao L, Xie X, Schmitt A, Arradaza N, Cippola M, Old M, Agrawal A, Ozer E, et al: Elevated intrinsic cancer stem cell population in human papillomavirus-associated head and neck squamous cell carcinoma. Cancer 120: 992-1001, 2014.

121. Zhang M, Zhuang G, Sun X, Shen Y, Wang W, Li Q and Di W: TP53 mutation-mediated genomic instability induces the evolution of chemoresistance and recurrence in epithelial ovarian cancer. Diagn Pathol 12: 16, 2017.

122. Chiche A, Moumen M, Romagnoli M, Petit V,Lasla H, Jézéquel P, de la Grange P, Jonkers J, Deugnier MA, Glukhova MA and Faraldo MM: p53 deficiency induces cancer stem cell pool expansion in a mouse model of triple-negative breast tumors. Oncogene 36: 2355-2365, 2016.

123. Shetzer Y, Molchadsky A and Rotter V: Oncogenic mutant p53 gain of function nourishes the vicious cycle of tumor development and cancer stem-cell formation. Cold Spring Harb Perspect Med 6: pii: a026203, 2016

124. Tan MJ, White EA, Sowa ME, Harper JW, Aster JC and Howley PM: Cutaneous $\beta$-human papillomavirus E6 proteins bind Mastermind-like coactivators and repress Notch signaling. Proc Natl Acad Sci USA 109: E1473-E1480, 2012.

125. Shamir ER, Devine WP, Pekmezci M, Umetsu SE, Krings G, Federman S, Cho SJ, Saunders TA, Jen KY, Bergsland E, et al: Identification of high-risk human papillomavirus and $\mathrm{Rb} / \mathrm{E} 2 \mathrm{~F}$ pathway genomic alterations in mutually exclusive subsets of colorectal neuroendocrine carcinoma. Mod Pathol 32: 290-305, 2019.

126. Dyson N, Howley PM, Münger K and Harlow E: The human papilloma virus-16 E7 oncoprotein is able to bind to the retinoblastoma gene product. Science 243: 934-937, 1989.

127. Shanmugarajah R, Bin W, Snow ET, Sharma P, Pavey D, Merrett N, Ball MJ, Brain T, Fernando R and Robertson IK: Transcriptionally active human papillomavirus is strongly associated with Barrett's dysplasia and esophageal adenocarcinoma. Am J Gastroenterol 108: 1082-1093, 2013.

128. Anders M, Rösch T, Küster K, Becker I, Höfler H, Stein HJ Meining A, Wiedenmann B and Sarbia M: Expression and function of the coxsackie and adenovirus receptor in Barrett's esophagus and associated neoplasia. Cancer Gene Ther 16: 508-515, 2009.

129. Chang F, Syrjänen S, Wang L and Syrjänen K: Infectious agents in the etiology of esophageal cancer. Gastroenterology 103 1336-1348, 1992.

130. Chang F, Syrjänen S, Shen Q, Ji HX and Syrjänen K: Human papillomavirus (HPV) DNA in esophageal precancer lesions and squamous cell carcinomas from China. Int J Cancer 45: $21-25,1990$ 
131. He Z, Xu Z, Hang D, Guo F, Abliz A, Weiss NS, Xi L, Liu F, Ning T, Pan Y, et al: Anti-HPV-E7 seropositivity and risk of esophageal squamous cell carcinoma in a high-risk population in China. Carcinogenesis 35: 816-821, 2014

132. Wang L, Li J, Hou J, Li M, Cui X, Li S, Yu X, Zhang Z, Liang W, Jiang J, et al: $\mathrm{p} 53$ expression but not p16(INK4A) correlates with human papillomavirus-associated esophageal squamous cell carcinoma in Kazakh population. Infect Agent Cancer 11: 19, 2016.

133. Ludmir EB, Stephens SJ, Palta M, Willett CG and Czito BG: Human papillomavirus tumor infection in esophageal squamous cell carcinoma. J Gastrointest Oncol 6: 287-295, 2015.

134. Xi R, Pan S, Chen X, Hui B, Zhang L, Fu S, Li X, Zhang X, Gong T, Guo J, et al: HPV16 E6-E7 induces cancer stem-like cells phenotypes in esophageal squamous cell carcinoma through the activation of PI3K/Akt signaling pathway in vitro and in vivo. Oncotarget 7: 57050-57065, 2016.

135. Syrjänen KJ: HPV infections and oesophageal cancer. J Clin Pathol 55: 721-728, 2002.

136. Halec G, Schmitt M, Egger S, Abnet CC, Babb C, Dawsey SM Flechtenmacher C, Gheit T, Hale M, Holzinger D, et al: Mucosal alpha-papillomaviruses are not associated with esophageal squamous cell carcinomas: Lack of mechanistic evidence from South Africa, China and Iran and from a world-wide meta-analysis. Int J Cancer 139: 85-98, 2016.
137. Yang L, Ji Y, Chen L, Li M, Wu F, Hu J, Jiang J, Cui X, Chen Y, Pang L, et al: Genetic variability in LMP2 and LMP7 is associated with the risk of esophageal squamous cell carcinoma in the Kazakh population but is not associated with HPV infection. PLoS One 12: $\mathrm{e} 0186319,2017$.

138. da Costa AM, Fregnani JHTG, Pastrez PRA, Mariano VS, Silva EM, Neto CS, Guimarães DP, Villa LL, Sichero L, Syrjanen KJ and Longatto-Filho A: HPV infection and p53 and p16 expression in esophageal cancer: Are they prognostic factors? Infect Agent Cancer 12: 54, 2017.

139. Kayamba V, Bateman AC, Asombang AW, Shibemba A, Zyambo K, Banda T, Soko R and Kelly P: S HIV infection and domestic smoke exposure, but not human papilloma virus, are risk factors for oesophageal squamous cell carcinoma in Zambia: A case-control study. Cancer Med 4: 588-595, 2015.

(i) (3) This work is licensed under a Creative Commons

EY No ND Attribution-NonCommercial-NoDerivatives 4.0 International (CC BY-NC-ND 4.0) License. 